\title{
Derecho laboral vs. Derecho cooperativo \\ Análisis sobre políticas públicas y derechos encontrados ¿Qué prevalece?
}

Labor law vs. Cooperative law Analysis of public policies and rights found What prevails?

Lei trabalhista vs. Direito cooperativo Análise de políticas públicas e direitos encontrados 0 que prevalece?

\section{Juan Enrique Santana Félix}

Recibido: 2 de junio de 2018 Aceptado: 11 de agosto de 2018

Publicado: 5 de abril de 2019

Cómo citar este artículo: Santana-Félix, J. (2019). Derecho laboral vs derecho cooperativo. Análisis sobre políticas públicas y derechos encontrados. ¿Quién prevalece? Cooperativismo \& Desarrollo, 27(1), 1-26. doi: https://doi.org/10.16925/2382-4220.2019.01.11

Artículo de investigación. https://doi.org/10.16925/2382-4220.2019.01.11

* Bufete Juan Enrique Santana Félix, Universidad de Puerto Rico, San Juan, Puerto Rico. Correo electrónico: abogadosantana@yahoo.com 


\section{Resumen:}

El presente trabajo pretende dar a conocer y generar discusión sobre un tema que ha surgido en Puerto Rico y posiblemente en otros países de Latinoamérica y del Caribe, aunque tal debate no nos consta ni hemos podido identificarlo allá de los mares, incluyendo alguna discusión sobre los efectos que pudiera tener en las distintas políticas públicas aprobadas por los Gobiernos Nacionales. Este debate por su relación con la clase obrera y la clase cooperativista tiene el potencial de provocar confrontaciones, intelectuales y doctrinales e impactar teorías y posiciones sobre la autonomía e independencia del cooperativismo, lo que nos impone la obligación de repensar el asunto y elevarlo a discusión pública incluyendo la necesidad de mejorar la educación en materia cooperativa y con mayor rigor en las personas que están obligadas a interpretar la legislación vigente y adoptar determinaciones sobre su alcance mas cuando tal política pública nace de una legislación social.

La realidad es que en nuestra Isla, Puerto Rico, existen varias escuelas de derecho, ninguna de las cuales requiere matricularse en un curso sobre derecho o educación cooperativa que no resulta ser un tema tan estudiado como lo es el derecho laboral y por tanto es muy poco probable que tengamos funcionarios judiciales o magistrados interesados o doctos en materia cooperativa, lo que presagia un disloque en las decisiones judiciales vis a vis la política pública vigente en favor del cooperativismo.

En los hechos estudiados en este escrito pretenderemos demostrar cómo la Legislación Cooperativa y por ende la política pública que de ella emana cede ante la Legislación Laboral impactando los derechos y obligaciones que surgen de las leyes vigentes, la autonomía de la voluntad, la libertad contractual y del acto cooperativo.

Palabras Claves: Derecho Cooperativo, Derecho Laboral, Políticas Públicas, Acto Cooperativo, Mesada, Autonomía de la Voluntad

\section{Summary:}

This work aims to raise awareness and generate discussion on a topic that has emerged in Puerto Rico and possibly other countries in Latin America and the Caribbean, although such a debate is not known or we have been able to identify it beyond the seas, including some discussion on the effects that could have in the different public policies approved by the National Governments. This debate because of its relationship with the working class and the cooperative class has the potential to provoke confrontations, intellectual and doctrinal and impact theories and positions on autonomy and independence of cooperativism, which imposes the obligation to rethink the issue and raise it to public discussion including the need to improve cooperative education and more rigorously in people who are forced to interpret the current legislation and adopt determinations on their reach more when such public policy is born of social legislation.

The reality is that in our Island, Puerto Rico, there are several law schools, none of which requires enrolling in a course on law or cooperative education that does not turn out to be a subject as studied as labor law and therefore is very It is unlikely that we have judicial officers or magistrates interested or learned in cooperative matters, which presages a dislocation in judicial decisions vis a vis the current public policy in favor of cooperativism.

In the facts studied in this paper we will try to demonstrate how the Cooperative Legislation and therefore the public policy that emanates from it yields before the Labor Legislation impacting the rights and obligations that arise from the laws in force, the autonomy of the will, the contractual freedom and of the cooperative act.

Key words: cooperative law, labor law, public policies, cooperative act, allowance, autonomy of the will 


\section{Resumo:}

Este trabalho tem como objetivo sensibilizar e gerar discussão sobre um tema que surgiu em Porto Rico e, possivelmente, outros países da América Latina e do Caribe, embora este debate não temos conhecimento nem temos sido capazes de identificá-lo além dos mares, incluindo alguma discussão sobre efeitos que poderiam ter nas diferentes políticas públicas aprovadas pelos governos nacionais. Esse debate por causa de sua relação com a classe trabalhadora e a classe cooperativa tem o potencial de provocar confrontos, teorias intelectuais e doutrinárias e de impacto e posições sobre autonomia.

e independência da cooperativa, que impõe a obrigação de repensar o assunto e elevá-la a discussão pública, incluindo a necessidade de melhorar a educação em matéria de cooperação e mais rigor em pessoas que são obrigadas a interpretar a lei e fazer determinações sobre o seu alcançar mais quando essa política pública nasce da legislação social.

A realidade é que, na nossa ilha, Puerto Rico, várias escolas de direito, nenhuma das quais exige a inscrição em um curso de direito ou educação cooperativa não ser um problema tão estudada como é o direito do trabalho e, portanto, muito susceptíveis de ter funcionários judiciais, juízes ou estudiosos interessados em matéria de cooperação, prenunciando uma luxação nas decisões judiciais vis a vis a política pública atual em favor da cooperação.

$\mathrm{Na}$ verdade estudado neste trabalho pretendemos mostrar lei como cooperativa e política, portanto, público que dele emana cede à Legislação Trabalhista impactando os direitos e obrigações decorrentes de leis existentes, a autonomia, a liberdade de contrato e do ato cooperativo.

Palavras-chave: direito cooperativo, direito do trabalho, políticas públicas, ato cooperativo, subsídio, autonomia da vontade

\section{Alcance de la Legislación Social como Política Pública}

La cita que a continuación reproduzco corresponde al ensayo titulado Geigel Polanco, Vicente. (1994), Bases, Naturaleza y Caracteres de la Legislación Social, San Juan, Puerto Rico, Departamento del Trabajo de Puerto Rico, Negociado de Publicaciones y Educación Obrera. Bases, Naturaleza y Caracteres de la Legislación Social, publicado en el libro "Legislación Social de Puerto Rico" por Vicente Géigel Polanco en una edición del año 1944 del Departamento del Trabajo de Puerto Rico, Negociado de Publicaciones y Educación Obrera y en parte lee:

"Toda legislación es social en el sentido de aplicarse o referirse a alguna actividad o relación de la vida en sociedad. Tal es el concepto amplio y general del vocablo. Aquí lo usaremos con una acepción más (sic) restringida. Por Legislación Social significaremos el conjunto de leyes, instituciones, actividades, programas de gobierno y principios destinados a establecer un régimen de justicia social a través de la intervención del Estado en la economía nacional, del mejoramiento 
de las condiciones de vida de la comunidad y de medidas para garantizar el disfrute de la libertad y el progreso general del pueblo.

En esta definición apuntaremos el objetivo básico de la Legislación Social: establecer un régimen de justicia para todas las clases sociales, que vale tanto como eliminar la explotación y el privilegio; procurar que los bienes físicos y espirituales de la civilización estén al alcance de todos y cimentar una estructura jurídica que haga factible la democracia como calidad de vida y de gobierno."

En nuestra Isla, tal y como ocurre en otros tantos lugares y gobiernos, se adopta legislación que produce política pública y en particular sobre dos de los temas a los que se refiere este trabajo, esto es, en materia laboral y en materia cooperativa, engendrando cada una de ellas un alcance que mandata y obliga a los responsables de hacer cumplir las leyes aunque parezcan encontradas o donde se genere una antinomia o derechos encontrados, adoptados, sancionados y promovidos por el propio Estado.

Sobre el alcance y la definición de las políticas públicas generadas por la legislación que cada País aprueba,Tamayo Sáez, Manuel. (1997), Capítulo 11, El análisis de las políticas públicas, Bañón, Rafael y Carrillo Ernesto (comps), Alianza Editorial, 1997, La nueva administración pública, Madrid, España, Tamayo Sáez nos indica que:

"[l]as políticas públicas son el conjunto de objetivos, decisiones y acciones que lleva a cabo un gobierno para solucionar los problemas que en un momento determinado los ciudadanos y el gobierno consideran prioritarios.

Desde este punto de vista, las políticas públicas se pueden entender como un proceso que se inicia cuando un gobierno o un directivo público detecta la existencia de un problema que, por su importancia, merece su atención y termina con la evaluación de los resultados que han tenido las acciones emprendidas para eliminar, mitigar o variar ese problema..." (Tamayo Sáez p. 281( 1997).

En materia de cooperativismo, la legislación adoptada por el Gobierno de Puerto Rico por medio de las distintas Administraciones Políticas de turno responde al reconocimiento de su autonomía e independencia y que se trata de un sistema socio económico que a través de la historia ha sabido adelantar sus causas libres de toda injerencia política. 
En el año 2001, la Organización de las Naciones Unidas (ONU) aprobó su Resolución 56/147 reconociendo que las cooperativas promueven la participación de todos en el desarrollo económico y social y en reacción a ello se han adoptado determinaciones de política pública abogando por entornos propicios para el desarrollo de las cooperativas igual ha ocurrido con otros organismos internacionales procurando que los gobiernos examinen sus leyes para garantizar a este tipo de organización, su protección y crecimiento de modo que ayuden a contribuir a la erradicación de la pobreza y al logro de una mayor integración social. De este modo, muchas de las políticas públicas aprobadas por los Parlamentos Nacionales han respondido a las guías y parámetros sugeridos por la onU y su Consejo Económico que viabilizan que las cooperativas participen en igualdad de condiciones con otras formas de empresas. No obstante, es mi opinión que la adopción de tales políticas públicas no es suficiente sino educamos a los sectores que por ley están obligados a interpretar la legislación vigente y acatar lo que en definitiva es la política pública que de ellas surge, en este caso sobre la materia del cooperativismo.

Igual acción ha adoptado el Parlamento Europeo quien en su informe sobre la contribución de las cooperativas a la crisis, solicitó a la Comisión Europea y a los Estados Miembros que se potencien las cooperativas y otras empresas que pertenecen a la economía social como herramientas para salir de la crisis ya que estas desempeñan un papel esencial en la economía. ${ }^{2}$

Por ello la importancia de los mecanismos provistos por el Estado ya que es a través de ellos que se adoptan las distintas disposiciones legales y normativas para que las cooperativas puedan contribuir a mejorar la calidad de vida de sus asociados, incluyendo las comunidades o el entorno donde se encuentran establecidas.

En Puerto Rico desde hace décadas se han adoptado leyes que rigen y regulan las instituciones cooperativas, pero a la luz de algunas decisiones judiciales quedamos obligados a repensar si se ha cumplido con las políticas públicas que emanan de las leyes aprobada por el Estado.

En la Resolución Número 193 sobre la Promoción de las Cooperativas, aprobada el 20 de junio de 2002 la ORGANIZACIÓN INTERNACIONAL DEL TRABAJO (OIT) resalta el significado de la palabra "cooperativa", para designar una asociación autónoma de personas unidas voluntariamente para satisfacer sus necesidades y aspiraciones económicas, sociales y culturales en común, a través de una empresa de propiedad conjunta y de gestión democrática reclamando a los gobiernos nacionales y a sus Parlamentos que adopten una serie de criterios como política en favor del Movimiento

\footnotetext{
1 Aprobada en la 88va., sesión ordinaria el 19 de diciembre de 2001.

2 Cooperativa de las Américas: Tomado de http://empresaytrabajo.coop
} 
Cooperativo. Es precisamente esa asociación voluntaria y autónoma la que queda en entredicho y que planteo en este trabajo a la luz de una decisión judicial que relaciona ambas ramas del derecho derechos, ; el cooperativo y el laboral.

\section{Estudio del Caso Puerto Rico}

Producto de nuestra experiencia litigando asuntos de derecho cooperativo donde se controvierten distintos temas relacionados con las cooperativas, nos vemos forzados a conocer la legislación aplicable incluyendo la intención legislativa para con ello conocer el alcance de la política pública existente. En dicho quehacer litigioso nos planteamos si las políticas públicas aprobadas por el Gobierno de Puerto Rico, se encuentran y confligen unas con otras, lo que nos motiva a analizar el tema y redactar este artículo dirigido a la comunidad jurídica para con ello obtener reacciones que pudiera ser de ayuda en la identificación de soluciones correctas y justas.

La relación de hechos que motiva este análisis surge en un caso donde una Cooperativa de Ahorro y Crédito reclamó su derecho a cobrar a una de sus asociadas la cantidad de dinero que le había prestado y que esta no había devuelto en clara violación a su deber como socia y al contrato de préstamo ${ }^{3}$ que regía entre las partes. Ante dicha conducta, la Cooperativa acudió ante el Tribunal de Primera Instancia para solicitar que se le concedieran los remedios a los que por ley tenía derecho provocando con ello que el Tribunal condenara por sentencia o dictamen a la socia a pagar la suma de dinero que le había tomado prestado a la institución y, a pesar de haber recaído una sentencia en su contra, la socia se negó a reembolsar el dinero tomado a préstamo a la Cooperativa obligando que esta iniciara un procedimiento de ejecución de sentencia que motivó una investigación e identificación de sus bienes para poder ejecutar la sentencia a través del embargo de cualquier objeto o bien de valor que existiera o donde tuviese alguna participación. Durante ese procedimiento

3 Art. 1044. Obligaciones que nacen de los contratos. (31 L.P.R.A. sec. 2994)

Las obligaciones que nacen de los contratos tienen fuerza de ley entre las partes contratantes, y deben cumplirse al tenor de los mismos.

Art. 1631 Contrato de préstamo, definición; comodato gratuito; préstamo gratuito o con interés. (31 L.P.R.A. sec. 4511)

Por el contrato de préstamo, una de las partes entrega a la otra, o alguna cosa no fungible para que use de ella por cierto tiempo y se la devuelva, en cuyo caso se llama comodato, o dinero u otra cosa fungible, con condición de volver otro tanto de la misma especie y calidad, en cuyo caso conserva simplemente el nombre de préstamo.

El comodato es esencialmente gratuito.

El simple préstamo puede ser gratuito o con pacto de pagar interés. 
post sentencia, la Cooperativa logró identificar que la demandada (socia dueña) tenía pendiente una reclamación judicial donde alegaba que había sido despedida de su trabajo en forma injustificada. Dicha reclamación fue presentada contra su anterior patrono que de prevalecer la convertiría en acreedora de una fuerte suma de dinero, por lo que la Cooperativa reclamó su derecho a intervenir en el pleito laboral a los fines de asegurar su acreencia declarada tal por sentencia.

La socia demandada se opuso a las pretensiones de la Cooperativa alegando que la demanda de intervención era improcedente en derecho porque aun cuando fuera cierta la deuda con la Cooperativa, existía un procedimiento sumario de reclamaciones laborales (Ley Núm. 2 de 17 de octubre de 1961)4, que no permitía por

4 Esta es una ley que establece y le reconoce al obrero una acción sumaria para que se atiende su reclamación en forma expedita, a saber:

Sec. 1. Reclamaciones laborales - Formulación de querella; partes; jurisdicción. (32 L.P.R.A. sec. 3118)

Siempre que un obrero o empleado tuviere que reclamar de su patrono cualquier derecho o beneficio, o cualquier suma por concepto de compensación por trabajo o labor realizados para dicho patrono, o por compensación en caso de que dicho obrero o empleado hubiere sido despedido de su empleo sin causa justificada, podrá comparecer, a su elección, ante la Sala del Tribunal de Distrito o del Tribunal de Primera Instancia, según sea el caso, del lugar en que realizó el trabajo o en que resida el obrero o empleado en la fecha de la reclamación y formular contra el patrono una querella que extenderá o llenará, según fuere el caso, el juez o el secretario del tribunal, en la cual se expresarán por el obrero o empleado los hechos en que se funda la reclamación.

En el ejercicio de cualquier acción que se pueda establecer acogiéndose al procedimiento fijado por las [29 LPRA secs. 3118 a 3132] de este título, el Secretario del Trabajo y Recursos Humanos podrá demandar, a iniciativa propia, o a instancia de uno o más (sic) trabajadores o empleados con interés en el asunto, y en representación y para beneficio de uno o más (sic) de los mismos que se encuentren en circunstancias similares, y también podrá constituirse en querellante o interventor en toda reclamación que se haya iniciado bajo el procedimiento establecido en las [29 LPRA secs. 3118 a 3132] de este título.

Podrán acumularse en una misma querella las reclamaciones de todos los obreros y empleados de un mismo patrono que hubieren dejado de percibir sus derechos, beneficios o salarios devengados en una obra común; Disponiéndose, que la presentación de una querella por uno o más (sic) obreros o empleados, o por el Secretario del Trabajo y Recursos Humanos en representación de ellos, no impedirá la radicación de otras acciones por o en representación de otros obreros o empleados.

El Tribunal de Distrito deberá conocer de toda querella en que la cuantía en controversia no exceda de diez mil $(10,000)$ dólares, sin incluir intereses, costas, gastos y honorarios de abogado, y el Tribunal de Primera Instancia deberá conocer de toda querella en que la cuantía en controversia exceda de diez mil $(10,000)$ dólares, sin incluir intereses, costas, gastos y honorarios de abogado; Disponiéndose, que si la querella se radicare en el Tribunal de Distrito y la cuantía en controversia excediere de diez mil $(10,000)$ dólares, sin incluir intereses, costas, gastos, y honorarios de abogado, el juez ordenará el traslado inmediato de la querella, si así lo solicitare cualquiera de las partes, para la Sala del Tribunal de Primera Instancia correspondiente, donde se verá el caso.

(Octubre 17, 1961, Núm. 2, p. 470, sec. 1; Mayo 30, 1984, Núm. 38, p. 108; Diciembre 24, 1998, Núm. 319, art. 1.) 
política pública este tipo de intervención en protección a los derechos del obrero. La Cooperativa afirmó que no intentaba intervenir en el asunto laboral objeto de la querella y que por el contrario deseaba y aspiraba a que mediante el procedimiento sumario se adjudicara la controversia a favor de la socia y que del dinero al que tuviere derecho, si alguno, por los conceptos alegados en su querella, se separara la suma de dinero que la socia le adeudaba sin que la Cooperativa corriera el riesgo de que una vez la socia fuera indemnizada, se negare a pagar y satisfacer la sentencia dictada por lo que se justificaba la presentación de la demanda de intervención donde reclamaba un derecho o expresaba tener un interés en el asunto objeto de litigio, cumpliendo además con el requisito de demostrar que tal derecho o interés pudiera, de hecho, quedar afectado por la disposición final del pleito, incluso en la etapa de ejecución de sentencia para lo cual citó los siguientes precedentes jurisprudenciales y doctrina: Aponte Caratini v. Román Torres, 145 D.P.R. 477 (1998) y al tratadista J.A. Cuevas Segarra, Tratado de Derecho de Procedimiento Civil, Tomo I, pág. 427 (Publicaciones J.T.S. 2000) y según establecido en la Regla 21.5 de las de Procedimiento Civil.

Afirmó que el criterio para determinar si se reconocía o no el derecho de intervención, debía ser práctico y no conceptual según el caso resuelto por el Tribunal Supremo Nacional en R. Mix Cocrete v. R. Arellano \& Co., 110 D.P.R. 869 (1981) donde se resolvió que:

“El criterio a utilizarse es de orden más (sic) pragmático. ¿Existe 'de facto' un interés que amerite protección? ¿Quedaría afectado, como cuestión práctica, tal interés por la ausencia del interventor en el caso? El análisis puede variar de pleito a pleito. En el fondo, la decisión depende del equilibrio a lograrse en la situación específica entre los valores en conflicto: el interés en la economía procesal representada por la solución en un solo pleito de varias cuestiones relacionadas entre sí y el interés en evitar que los pleitos se compliquen y eternicen innecesariamente". Chase Manhattan, supra, a la pag. 770. La Regla 21.4 a su vez establece el procedimiento a seguir para solicitar al Tribunal que autorice la intervención:

"Toda persona que desee intervenir, notificará su solicitud de intervención a todas las partes conforme lo dispuesto en la Regla 67. La solicitud expondrá las razones en que se base y se acompañará de una alegación en que se establezca la reclamación o defensa que motive la intervención" 
ás arguyó que las Reglas de Procedimiento Civil de Puerto Rico establecían y regulaban el mecanismo procesal de la intervención diseñado para ofrecer protección a personas que no fueron parte inicial en un pleito pero que sus derechos podrían verse afectados indicando además que dichas reglas procesales tenían que interpretarse liberalmente y que el criterio para determinar si se reconocía o no el derecho de intervenir era uno de naturaleza práctica y no conceptual citando con aprobación a $\underline{\mathrm{R}}$. Mix

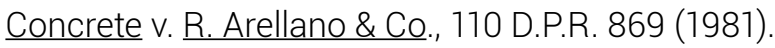

En cuanto a la Ley Núm. 2 de 17 de octubre de1961, la Cooperativo alegó y reiteró en su Oposición a la Moción de Desestimación que como parte interventora no le interesaba en lo absoluto retrasar la adjudicación en sus méritos de la reclamación presentada por la querellante recurrida, y que tampoco interesaba afectar ninguna de las intenciones que tuvo la Asamblea Legislativa al aprobar la Ley Núm. 2, supra, por el contrario, interesaba que de inmediato se dictara sentencia a favor de la socia, advirtiéndole al Tribunal que su interés era que de cualquier cantidad de dinero que en su día se le pudiera reconocer a la socia, se separara la suma de dinero que por contrato (pagaré) y por sentencia se le adeudaba a la Cooperativa, de la cual no solamente era socia sino dueña, y que la oposición a la solicitud de intervención presentada por esta no encontraba cabida en el estado de derecho vigente y era contrario a la política pública adoptada por el Estado en materia cooperativa y que atender su solicitud para que se desestimara la demanda de intervención presentada por la Cooperativa provocaría un desvarío a la justicia afectando la rápida disposición y la economía procesal del caso.

El Tribunal de Primera Instancia declaró no ha lugar la Demanda de Intervención presentada por la Cooperativa indicando en forma escueta que debido a que el caso era uno de índole laboral existía como política pública un proteccionismo a favor del obrero lo que obligó a la Cooperativa a presentar una reconsideración de dicho dictamen incluyendo un planteamiento nunca antes considerado por ningún Tribunal Apelativo en Puerto Rico en cuanto al concepto del acto cooperativo, la relación de la obrera y socia con la Cooperativa, las disposiciones de la Ley 255 de 28 de octubre de 2002 conocida como Ley General de Sociedades Cooperativas de Ahorro y Crédito de Puerto Rico ${ }^{5}$, que regulaban las relaciones entre la socia con su Cooperativa incluyendo lo dispuesto en la política púbica aplicable a cooperativas de ahorro y crédito, sin embargo, y aun sin oposición a la moción de reconsideración, el Tribunal la declaró no ha lugar sin expresar justificación o sostener en derecho su determinación.

5 De esta Ley Especial surgen las obligaciones que automáticamente le son requeridas a las personas que en forma libre y voluntaria deciden hacerse socios de la Cooperativa y que son citadas mas adelante en este trabajo. 
En desacuerdo, la Cooperativa acudió en alzada de dicho dictamen ante el Tribunal de Apelaciones de Puerto Rico alegando que el Tribunal de Primera Instancia incidió al desestimar su demanda de intervención, al no determinar que hubo una violación al Acto Cooperativo y a las leyes vigentes aplicables a las cooperativas en Puerto Rico de donde emana la política pública sobre cooperativismo pero el Tribunal de Apelaciones ${ }^{6}$ declaró no ha lugar el Recurso de Certiorari o Revisión y determinó que la Ley Núm. 2, supra, proveía un procedimiento expedito para la tramitación de las reclamaciones de un empleado contra su patrono por " cualquier derecho o beneficio, o cualquier suma por concepto de compensación por trabajo o labor realizados para dicho patrono, o por compensación en caso de que dicho obrero o empleado hubiere sido despedido de su empleo sin causa justificada“, 32 L.P.R.A. sec. 3118 donde se cita con aprobación la norma jurisprudencial, Lucero v. San Juan Star, 159 D.P.R. 494, 503-504 (2003).

Añadió que la política pública establecida mediante este procedimiento sumario (Ley Núm. 2) era propiciar la celeridad en la adjudicación de las reclamaciones de un empleado contra su patrono, para garantizar al obrero la pronta vindicación de sus derechos, de la forma menos onerosa posible y proveerle certeza en cuanto a su situación económica y laboral, citando con aprobación varias decisiones del Tribunal Supremo de Puerto Rico, entre ellas; Aguayo Pomales v. R \& G Mortgage, 169 D.P.R. 36, 43 (2006); Ríos v. Industrial Optic, 155 D.P.R. 1 (2001) y Mercado Cintrón v. Zeta Comm., Inc., 135 D.P.R. 737 (1994).

En defensa de su dictamen, el Panel de Jueces del Tribunal de Apelaciones indicó que el procedimiento sumario se distinguía por: (1) términos cortos para la contestación de la querella presentada por el obrero o empleado; (2) criterios para la

6 El Tribunal de Apelaciones revisa las sentencias y dictámenes del Tribunal de Primera Instancia, además de las decisiones finales de las agencias administrativas. La Ley de la Judicatura de 1992 creó el Tribunal de Apelaciones como un tribunal intermedio entre el Tribunal de Primera Instancia y el Tribunal Supremo. La sede del Tribunal está en San Juan, Puerto Rico. El Tribunal de Apelaciones conocerá de los siguientes asuntos:

\section{Apelación}

Mediante el recurso de Apelación, el Tribunal revisa toda sentencia o dictamen final, sea civil o criminal, dictada por el Tribunal de Primera Instancia.

\section{Certiorari}

Mediante Certiorari, el Tribunal revisa las resoluciones interlocutorias (no finales) dictadas por el Tribunal de Primera Instancia, así como las Sentencias de ese Tribunal relacionadas con la Ley de Municipios Autónomos del Estado Libre Asociado de 1991, en revisión de los laudos de arbitraje, procedimientos de jurisdicción voluntaria y las dictadas como consecuencia de una alegación de culpabilidad. Además, el Tribunal de Apelaciones entenderá en aquellos casos mencionados la nueva vigencia de las Regla 52.1 del Procedimiento Civil.http://www.ramajudicial.pr/sistema/apelaciones.htm 
concesión de una sola prórroga para contestar la querella; (3) un mecanismo para el emplazamiento del patrono querellado; (4) el procedimiento para presentar defensas y objeciones; (5) criterios para la aplicación de las Reglas de Procedimiento Civil; (6) una limitación específica sobre el uso de los mecanismos de descubrimiento de prueba; (7) una prohibición específica de demandas o reconvenciones contra el obrero o empleado querellante; (8) la facultad del Tribunal para dictar sentencia en rebeldía cuando el patrono querellado no cumpla con los términos provistos para contestar la querella, y (9) los mecanismos para la revisión y ejecución de la sentencia y el embargo preventivo citando a Patiño Chirino v. Parador Villa Antonio, 2016 TSPR 200, 196 D.P.R. ---- (2016); Medina Nazario v. McNeil Healthcare, LLC, 194 D.P.R. 723 (2016); Rivera v. Insular Wire Products Corp., 140 D.P.R. 912, 923-924 (1996). Nótese que todo este proceso se refiere al patrono querellado y no a terceros.

Señaló además que la Ley Núm. 2, supra, disponía que en los pleitos tramitados al amparo del procedimiento sumario, se aplicarían las Reglas de Procedimiento Civil en todo aquello que no estuviese en conflicto con las disposiciones específicas de las mismas o con el carácter sumario del procedimiento por lo que resolvió que la demanda de intervención presentada por la Cooperativa, aun cuando entre ella y la socia existía una relación contractual que se regía por sus propios términos y condiciones y a pesar de la política pública en materia de cooperativismo de donde emana el reconocimiento de derechos y obligaciones que se le imponen a los socios, no era procedente debido a la naturaleza sumaria de la reclamación laboral, resolviendo específicamente que “la presentación de una solicitud de intervención sobre cobro de dinero de un pleito ajeno a la reclamación laboral tramitada bajo el procedimiento sumario, era contraria a los propósitos que perseguía la legislación laboral, lo que impedía su trámite bajo este caso."

\section{Argumentos:}

Por años el Gobierno de Puerto Rico ha adoptado medidas legislativas convertidas en ley creando una variedad de políticas públicas a favor del cooperativismo puertorriqueño y de los principios universales que rigen a cualquier organización cooperativa, todas ellas basadas en la doctrina Rochdale que exige que las cooperativas observen el cumplimiento de siete principios básicos, como lo son: adhesión libre y voluntaria; control democrático por parte de los socios; participación económica de los socios; autonomía e independencia; educación, capacitación e información; cooperación entre cooperativas y responsabilidad social. Estos principios son los que convierten a las cooperativas en organizaciones distintas a las empresas u organizaciones cuya 
finalidad es el lucro y promueven e incentivan a sus asociados para lograr excedentes que posteriormente se podrían capitalizar para continuar mejorando la oferta de servicios o sean repartidos entre ellos mismos, todo ello sin la intervención del Estado buscando y promoviendo una mayor eficiencia y efectividad en sus quehaceres diarios.

Para comprender mejor a las organizaciones cooperativas, que los Tribunales de Primera Instancia y de Apelaciones le negaron el derecho a intervenir, es importante comprender que todas las cooperativas son empresas sin fines de lucro y de servicios por lo que son distintas a las corporaciones regulares cuyas aspiraciones son las ganancias y que con los esfuerzos de sus asociados producen excedentes o sobrantes, que surgen de un exceso en el precio que cobró la cooperativa a sus asociados por la prestación de sus servicios y que revierte a sus asociados en forma de acciones ayudando a capitalizar a la propia cooperativa y aumentando su participación como socio de la Cooperativa. Para que eso pueda ser posible, el socio dueño de la cooperativa no solamente tiene que cumplir con las obligaciones contractuales que en forma libre y voluntaria contrajo con la cooperativa cuando decidió hacerse socio sino además con la aportación anual a su cuenta de acciones conforme lo requiere la ley nacional aplicable a las cooperativas de ahorro y crédito.

En cuanto a las políticas públicas adoptadas por el Gobierno de Puerto Rico en materia de cooperativismo, políticas que obligan a los poderes constitucionales, incluyendo a ambos Foros Judiciales, según la definición que nos ofrece Tamayo (1997) , tales políticas al parecer no representar ser la solución a los problemas planteados en este escrito Tamayo destaca que estas políticas

"...son el conjunto de objetivos, decisiones y acciones que lleva a cabo un gobierno para solucionar los problemas que en un momento determinado los ciudadanos y el gobierno consideran prioritarios. Desde este punto de vista, las políticas públicas se pueden entender como un proceso que se inicia cuando un gobierno o un directivo público detecta la existencia de un problema que, por su importancia, merece su atención y termina con la evaluación de los resultados que han tenido las acciones emprendidas para eliminar, mitigar o variar ese problema".

En materia de cooperativismo, la legislación adoptada por décadas por los distintos Gobiernos responde al reconocimiento de su autonomía e independencia y que se trata de un sistema socio económico que ha sabido adelantar sus causas, libre de toda injerencia particularmente política, pero contando con que la adopción de 
aquellas normas que constituyen y forman una política pública le permita y haga viable su desarrollo. Es mediante tales mecanismos provistos y aprobados por el Estado a través de legislación especial y convertida en política pública, que se debería lograr el desarrollo de normas jurídicas y prácticas judiciales considerando para ello la política pública existente y no contradiciéndola y reconociendo que el cooperativismo enmarca una concepción única de solidaridad que demanda y exige esfuerzo propio, ayuda mutua y desprendimiento. Para que eso pueda ser posible sería necesario una educación a todos los niveles y especialmente a los magistrados, jueces y paralegales que intervienen en estas controversias (jurídico-legales).

Las Leyes 255 de 2002 y 239 de 2004 que son las que regulan a las cooperativas en Puerto Rico recogen preceptos de la Doctrina Cooperativista a nivel internacional y nacional por lo que pretender ignorar esa política pública y menoscabar las facultades que le son reconocidas como persona jurídica con capacidad para contratar, demandar y ser demandada, las ubica en una posición de desventaja y de menoscabo de sus derechos contractuales que en este caso castiga al socio dueño, común y humilde, que no es otro que aquél que principalmente proviene de la clase pobre y trabajadora que depende que los demás asociados cumplan en forma estricta con las obligaciones económicas que contrajeron con sus organizaciones de las que son sus dueños incluyendo las obligaciones legales que emanan de las propias leyes que les aplican, incumplimiento que pudiera afectar o eliminar el ofrecimiento de servicios, afectar la diversificación de los servicios o en el caso de las cooperativas de ahorro y crédito, disminuir el potencial de generar mayor capital que se utiliza para ampliar el ofrecimiento de financiamientos, actividad que la banca privada ha disminuido o restringido debido a la crisis económica que atravesamos, teniendo que las cooperativas llenar ese espacio.

Sobre el alcance en particular de la política pública adoptada por el Estado en materia del cooperativismo de ahorro y crédito, destacamos lo que surge de la Exposición de Motivos de la Ley 255-2002, supra:

\footnotetext{
“Es política pública del Estado Libre Asociado encaminar el desarrollo social y económico de Puerto Rico al amparo de los principios de justicia social, esfuerzo propio y control democrático del cooperativismo.

Por ello, el Movimiento Cooperativo constituye una pieza integral y un fuerte pilar para el desarrollo económico y social del país. Razón por la
} 
cual, el crecimiento y fortalecimiento del cooperativismo en Puerto Rico

está revestido de alto interés público." (Énfasis y subrayado suplido).

De tales expresiones surge sin temor a equivocaciones el alcance que la Asamblea Legislativa tuvo al aprobar la actual legislación incluyendo lo dispuesto en el Artículo 1.02 sobre la declaración de su política pública actual en esta materia tan importante para el desarrollo socio económico de nuestra Isla, a saber:

\section{“Artículo 1.02 - Declaración de Política Pública}

Es política pública del Estado Libre Asociado de Puerto Rico facilitar y adelantar el crecimiento y fortalecimiento de las cooperativas de ahorro y crédito organizadas al amparo de esta Ley, propiciar una amplia y plena participación en los mercados de servicios financieros y fomentar la ampliación de la filosofía y principios cooperativos. Disponiéndose que, el Estado Libre Asociado de Puerto Rico y sus dependencias Ilevarán a cabo la implantación, aplicación e interpretación de esta Ley de conformidad con, y a los fines de adelantar, esta política pública.

Ante tan claras expresiones de nuestra Asamblea Legislativa avaladas por el Poder Ejecutivo surge que la Ley 255, supra, representa desde hace mas de 15 años lo que es la política pública en materia de cooperativismo financiero en Puerto Rico, lo que no debió ser pasado por alto por los Foros Judiciales que intervinieron en la controversia, cuando como en los hechos antes narrados surge una confrontación de políticas públicas, una a favor de un obrero trabajador que a su vez es socio de una cooperativa y otra relacionada con las obligaciones que tienen los socios dueños de una cooperativa. En dicho caso, ambos Tribunales concluyeron que tratándose de un asunto de índole laboral existía un proteccionismo a favor del obrero, pasando por alto que fue ese mismo obrero quien en forma libre y voluntaria accedió a ser socio y dueño de la Cooperativa de Ahorro y Crédito y en consecuencia se allanó y consintió a que se le aplicaran todas las disposiciones de la Ley 255, supra, particularmente aquellas disposiciones que surgen del Artículo 4.03 y que en su parte pertinente leen como sigue: 
"Artículo 4.03 - Obligaciones de los Socios

Todo socio de una cooperativa tendrá, respecto de la misma, las siguientes obligaciones:

(a) cumplir con las cláusulas de incorporación, con el reglamento general y con las obligaciones impuestas en ésta Ley;

(b) efectuar las aportaciones periódicas a la cuenta de acciones según lo disponga el reglamento general de la cooperativa. Las cooperativas estarán autorizadas a incluir el pago periódico de dichas aportaciones según requeridas en el reglamento general como parte de los pagos de préstamos que se le concedan a los socios y a efectuar descuentos directos de las cuentas de depósito para efectuar dichas aportaciones;

(c) velar por los intereses de la cooperativa y por el buen crédito y confianza pública de la misma;

(d) cumplir con todo contrato, convenio, compromiso u obligación social o pecuniaria que contraiga con la cooperativa; y

(e) desempeñar responsablemente las funciones de los cargos para los cuales sea electo o designado y asistir puntualmente a las reuniones de los comités a que pertenezca.

El Artículo 11.03 de la Ley 255-2002, supra, nos refiere a las disposiciones de la Ley 239-2004, según enmendada, ley que se convierte en derecho supletorio y que igual contiene una política pública a favor del Movimiento Cooperativo de Puerto Rico y donde destaca que las cooperativas se basan en los valores de ayuda mutua, responsabilidad, democracia, igualdad, equidad y solidaridad y de cuya Exposición de Motivos surge que la política pública del Estado Libre Asociado de Puerto Rico es encaminar el desarrollo social y económico del país al amparo de los principios de justicia social, esfuerzo propio y control democrático del cooperativismo constituyendo el Movimiento Cooperativo una pieza integral y un fuerte pilar para el desarrollo económico y social del país por lo cual, el crecimiento y fortalecimiento del cooperativismo en Puerto Rico quedó revestido desde hace décadas de un alto interés público. 
De dicha legislación surge además otra expresión que refleja una fuerte política pública a favor de las cooperativas, a saber:

\section{“CAPITULO 2. - POLÍTICA PÚBLICA}

Artículo 2.O. - Autonomía (5 L.P.R.A. § 4382) El Estado Libre Asociado de Puerto Rico garantiza el libre desenvolvimiento y la autonomía de las cooperativas. En armonía buscará la forma y manera de ayudar, estimular, desarrollar, promover y dar apoyo al movimiento cooperativo.

Artículo 2.1. — Igualdad de Derechos (5 L.P.R.A. § 4383) El Estado Libre Asociado de Puerto Rico garantiza que las cooperativas gozarán de todas las facultades y prerrogativas que la ley concede a otras personas jurídicas y que no se establecerán restricciones que sean discriminatorias o exigencias adicionales para éstas.

Artículo 2.2. - Derecho Aplicable (5 L.P.R.A. § 4384) Las cooperativas organizadas de conformidad con esta Ley se regirán por sus disposiciones $y$, en general, por el Derecho Cooperativo 7 . Supletoriamente se regirán por el derecho que les sea aplicable en cuanto sea compatible con su naturaleza.

Artículo 2.3. - Actos Cooperativos (5 L.P.R.A. § 4385) Son actos cooperativos los realizados entre las cooperativas y sus socios, o por las cooperativas entre sí, con el Estado Libre Asociado de Puerto Rico, en cumplimiento con su objetivo social, regidas por el Derecho Cooperativo." (Subrayado suplido).

\section{Importancia del Acto Cooperativo}

El acto cooperativo es una especie dentro del género de actos jurídicos que es distinguible de todos los demás actos. Este fue propuesto por primera vez, en 1954 por el jurista mexicano Antonio Salinas Puente que lo definió como el supuesto jurídico, ausente de lucro y de intermediación, que realiza la organización

7 Derecho cooperativo es el conjunto de normas especiales, jurisprudencia, doctrina y prácticas basadas en los principios que determinan y regulan la actuación de las organizaciones cooperativas y los sujetos que en ellas participan. 
cooperativa en cumplimiento de un fin preponderantemente económico y de utilidad social. Antonio Salinas Puente, Editorial Cooperativismo, México, 1954, p.127. El comentarista, Armando Arturo Moirano, según citado en la obra de lacovino, Hugo Horacio (2006). El acto cooperativo a treinta años de vigencia en la Argentina. Documento de Trabajo $\mathbf{N}^{\circ}$ 146, Universidad de Belgrano, ${ }^{8}$ nos ilustra indicando que "para llenar sus fines, la cooperativa se vale del llamado «acto cooperativo" que es toda operación realizada entre las cooperativas y sus asociados, en cumplimiento del objeto social, sin fines de lucro, ...

Según Pastorino (1993), " el acto cooperativo es un negocio jurídico unilateral, colegiado y complejo" que constituye "... la expresión jurídica de la solidaridad, del esfuerzo propio y de la ayuda mutua, diferenciándose del negocio jurídico ordinario en el que prima el enfrentamiento entre las partes..." Pastorino, Roberto Jorge, (1993), Teoría General del Acto Cooperativo, INTERCOOP Editora Cooperativa Ltda., Buenos Aires, p. 27 y 34.

En cuanto al contenido del acto cooperativo, ya en 1976 los especialistas en la materia establecían en la denominada Carta Jurídica de San Juan que: "El acto cooperativo - analizado mediante la abstracción de notas circunstanciales - contiene ciertos elementos objetivos básicos que lo caracterizan por su propia naturaleza, independientemente de las definiciones legales que se pudieran formular al respecto. Se advierte, en principio, la presencia de los siguientes elementos que integran la noción del acto cooperativo: a. necesidades individuales comunes; b. propósito de obrar conjuntamente; c. solidaridad; ${ }^{9}$ d. servicio sin finalidad de lucro; e. bienestar general;" según surge del Documento Final del II Congreso Continental de Derecho Cooperativo, Organización de Cooperativas de América, San Juan de Puerto Rico, publicado como Carta Jurídica de San Juan, II Congreso Continental de Derecho Cooperativo, Año 1966, Vol. 3, No 11, an Juan de Puerto Rico Revista de Idelcoop.

Respecto, de los efectos que se busca lograr con la consagración expresa del acto cooperativo, indica Lamenza, A. (2016) en su escrito El acto cooperativo. Noción, contenido y alcances. Su incorporación en el derecho positivo nacional ${ }^{10}$ son:

a) Establecerunconceptooinstitutojurídicoespecífıcodelderechocooperativo que tenga en cuenta sus particularismos. b) A través del mismo difundir y

8 Disponible en la red: $h$ ttp://www.ub.edu.ar/investigaciones/dt_nuevos/146_iacovino.pdf,

9 Según la definición de la estudiosa en esta materia la solidaridad es la satisfacción de necesidades individuales comunes: es el objeto del acto cooperativo. Cuesta, Elsa, (2000), Manual de Derecho Cooperativo, Ed. Abaco, Bs. As. , pp. 42 a 44,

10 https://www.aciamericas.coop/IMG/pdf/alfredolamenza.pdf 
facilitar el desarrollo y enseñanza del derecho cooperativo. c) Fundamentar la autonomía del derecho cooperativo. d) Determinar la jurisdicción competente en materia cooperativa. e) Normar de manera específica la vinculación entre las cooperativas y sus asociados o con otras cooperativas. f) Establecer un marco conceptual que permita demostrar el particularismo jurídico del vínculo cooperativo entre la cooperativa y sus socios para la interpretación y correcta aplicación de la normativa tributaria. g) Establecer un marco conceptual que permita demostrar el particularismo jurídico del vínculo cooperativo entre la cooperativa y sus socios para la interpretación y correcta aplicación de la normativa de otras ramas del derecho como, por ejemplo, la defensa del consumidor. 8) Establecer un marco jurídico y conceptual que permita justificar la obtención de determinados beneficios estatales para las entidades cooperativas.

Según lo describe Lamenza, (2016), supra:

.... tendríamos entonces que el acto cooperativo es el negocio jurídico que crea, modifica o extingue obligaciones, realizado por la cooperativa en cumplimiento de su objeto social con sus socios, con los socios de sus cooperativas socias, o por las cooperativas entre sí cuando estuviesen asociadas o vinculadas por pertenencia a otra de grado superior. Tiene por función económica la ayuda mutua, y se rige por el derecho cooperativo y el estatuto social.

En consecuencia, aplicando esa doctrina a los hechos antes narrados y que motivan este escrito es forzoso concluir que la socia quedó obligada no solamente por el acto cooperativo el cual reconoció y se allanó al solicitar el préstamo con la Cooperativa de Ahorro y Crédito, dinero que viene y está obligada legalmente a devolver a los asociados de dicha cooperativa, conforme al pagaré suscrito que manifiesta y refleja la autonomía de la voluntad ${ }^{11}$ que reguló además los intereses de su persona con la

11 *...Cabe destacar que, en Puerto Rico, el principio de la autonomía de la voluntad contractual es piedra angular de nuestro sistema económico. El principio nos dice que, en materia de contratos, rige la libertad de contratación entre las partes. $Y$ es que nuestro ordenamiento jurídico ha brindado gran libertad de acción a los particulares que desean obligarse, reconociéndoles una autónoma voluntad para ello. Claro está, dicha autonomía no es ilimitada, pues es nulo un contrato que resulte contrario a las leyes, a la moral o al orden público. Ese principio no tendría la importancia que reviste en nuestro ordenamiento económico, si no tuviere como contraparte el de la inalterabilidad del contenido del contrato (pacta sunt servanda). Éste principio postula que los pactos entre contratantes tienen fuerza de ley y deben ser cumplidos, sin que su validez 
Cooperativa y que se relacionan en el mismo, dando lugar al nacimiento, modificación o extinción de relaciones jurídicas. Por tanto, al negarse a cumplir con la devolución del dinero prestado, y habiendo recaído una sentencia en su contra, la Cooperativa estaba legitimada a intervenir y cobrar cualquier cantidad de dinero a la que pudiera tener derecho la socia reclamada, si alguno, siendo nuestra opinión que ese acto cooperativo existirá y perdurará en tanto el negocio jurídico en cumplimiento del objeto rija y vincule a la cooperativa y el asociado, lo que no debieron pasar por alto ambos Foros Judiciales.

Dentro de la noción de lo que es y significa el acto cooperativo se encuentra la creación, modificación o extinción de obligaciones, negocios dispositivos en sentido amplio o en sentido estricto que incluye pero no se limita a lo que en los hechos de la demanda de intervención mencionaba la Cooperativa sobre el préstamo que en forma libre y voluntaria y en pleno ejercicio de la autonomía de la voluntad tomó la demandada con la Cooperativa y quien se negó a cumplir con sus obligaciones, dentro de lo que es el Derecho Cooperativo Puertorriqueño, obligación que los Foros Judiciales pasaron por alto al ignorar la política pública vigente en materia de cooperativismo por lo que se planteó sin éxito que en ausencia de disposiciones particulares, en todo lo que no esté previsto en las leyes cooperativas se deberían aplicar al acto cooperativo los principios generales en materia de negocio jurídico en general y de los contratos en particular, en lo compatible y en cuanto correspondiere o fuere pertinente.

Resolver, como en efecto ocurrió, que por ser la controversia una de índole laboral automáticamente merecía un proteccionismo a favor del obrero obligando a los estudiosos del derecho cooperativo, a que colijamos con ello que tal proteccionismo es contrario a la política pública en materia de cooperativismo y de las obligaciones legales que en forma clara surge del Artículo 4.03 de la Ley 255-2002, supra, del contrato de préstamo suscrito, en forma libre y voluntaria por la demandada que se rige por sus propios términos y condiciones, de la libertad de contratación, de la autonomía de la voluntad y en adición a los propios términos de la sentencia, es una conclusión que en nuestra opinión no es compatible con el estado de derecho vigente ni con la doctrina cooperativa.

\footnotetext{
y cumplimiento pueda quedar al arbitrio de uno sólo de ellos. Así nos hemos expresado en torno al referido principio:

[c]ompromiso y rigor es el tenor de este principio. Las partes se obligan a todos los extremos de lo pactado que sean conformes a la ley, a la moral y al orden público. Por otro lado, la atadura o vínculo contractual tiene sus límites en la voluntad expresa de las partes y, claro está, en todo aquello que sea derivado de las expectativas razonables de lo que la buena fe dicta respecto a la relación contractual." citado con aprobación en el caso resuelto por el Tribunal Supremo de Puerto Rico: Collazo Vázquezv. Huertas Infante, 2000 TSPR91, 171 DPR 84
} 
Lo anterior nos obliga a analizar la política pública en materia de derecho laboral $^{12}$ y en particular el derecho a solicitar una mesada en casos donde el despido del empleado se haya producido injustificadamente. Veamos:

\section{Derechos Fundamentales, Carta de Derechos y Mesada:}

La Constitución de Puerto Rico en sus Secciones 16, 17 y 18 de la Carta de Derechos no reconoce ni establece un derecho fundamental a recibir una mesada y menos a que esta tenga una protección contra embargos. De esta Carta de Derechos surgen protecciones sobre condiciones de trabajo y las que establecen formas que puede utilizar el trabajador para preservar y mejorar sus condiciones de trabajo pero no para impedir que una Cooperativa o terceros exijan el cumplimiento estricto de las obligaciones que nacen de un contrato y que están protegidas por ley y que constituyen una fuerte política pública del Estado en cuanto a las obligaciones que ese mismo trabajador tiene que cumplir mas aun cuando tales obligaciones las asumió en forma libre y voluntaria y cuando le hizo representaciones a la entidad de la cual es socio y dueño.

Ese derecho a la mesada fue objeto de una resolución por parte del Tribunal Supremo de Puerto Rico que refleja un tanto su alcance, a saber:

"Para el trabajador, partícipe en los frutos de la empresa, para quien no hay liquidación de dividendos, ni beneficios, ni intereses acumulados en la digna faena de ganar con su esfuerzo el pan que parte en la mesa con los suyos, para quien el ahorro es ilusión devorada por la estrechez, la indemnización por despido es importante factor de producción. Cuando el desempleo condena a un ser humano y a su familia al hambre o a la indignidad, hay que llegar a límites de exigencia para privarle de la protección que ha ganado acceso a nuestra legislación social. Grave ha de ser la falta para cancelar los modestos auxilios destinados a sostener la familia en la transición a un nuevo empleo sin convertirse en carga para el Estado. Cristalina debe ser la justificación que se ofrezca para despedirlo sin este mínimo abono a sus años de servicio que representan la inversión de su único haber en la estructura

12 En Freire Ayala v. Vista Rental to Own, Inc. 2006 JTS 172 se indicó que la legislación protectora del trabajo establece la política pública del Estado en lo que concierne a los derechos básicos de los empleados en Puerto Rico. 
de producción: sus energías, su capacidad física e intelectual durante los años más (sic) fecundos, en fin, su salud que declina con el tiempo."13

La Ley 43 de 25 de abril de 1930 fue la primera ley que concedió el derecho del empleado contratado por tiempo indeterminado que hubiese sido despedido sin justa causa. Esa legislación, como su progenie de leyes, el único remedio que concedía y concede al trabajador que prevaleciera en una reclamación por despido injustificado, era y es una compensación económica. Luego fue aprobada la Ley de la Mesada, conocida como la Ley 80 de 30 de mayo de 1976, 29 L.P.R.A. Secs 185 A y siguientes que igual se considera una de las que forma parte de la Legislación Protectora del Trabajo que constituye uno de los mecanismos que el Estado le ofrece al trabajador para proteger, reclamar o mejorar sus condiciones de trabajo.

En los hechos narrados, la socia hizo uso de su derecho a solicitar la protección de su empleo a través de la prohibición de que el patrono alegadamente la despidiera sin justa causa, lo que en el mejor de los escenarios, provocaría la concesión de un beneficio económico conocido como la "mesada" pero a "contrario sensu", la Cooperativa igual hace uso de su derecho de acudir ante el Sistema de Justicia para reclamar que se honren y respeten las políticas púbicas adoptadas por los Poderes Legislativos y Ejecutivo con la aprobación de las Leyes 255-2002 y 239-2004, según enmendadas, incluyendo sus leyes antecesoras Leyes 5 y 6 de 1990, según enmendadas, y que además se le permita la ejecución de la sentencia dictada a su favor incluyendo el embargo de bienes que pertenezcan a la persona demandada.

En tales casos, aquellos trabajadores que deciden hacer uso de la legislación protectora acuden al Foro Judicial o Administrativo para reclamar únicamente la concesión de un remedio económico, que muy bien puede o no ser concedido garantizándosele el derecho de acudir al foro de su selección a solicitar tal remedio, lo que no puede hacer o pretender hacer es ir en contra de sus propios actos y de los derechos y obligaciones que legalmente contrajo en un claro acto de libertad contractual y que surgen del Contrato de Préstamo que suscribió con la empresa de la cual es socio y es dueño y que ese mismo trabajador, en esa calidad de socio de la Cooperativa quedó obligado por el "acto cooperativo", concepto que el Tribunal en su determinación declarando no ha lugar la Demanda de Intervención ignoró y pasó por alto y ni tan siquiera lo menciona, aun cuando el "acto cooperativo" forma parte de la Ley 239-2004, supra, y en consecuencia parte de la fuerte política pública del Estado Libre Asociado de Puerto Rico a favor del Movimiento Cooperativo Puertorriqueño siendo

13 Opinión del Tribunal Supremo de Puerto Rico; Quirós v. ITT, 108 DPR 536 (1979), expresándose sobre la compensación por despido injustificado bajo la Ley Núm. 80 de 30 de mayo de 1976. 
esta una política pública arraigada desde hace décadas en nuestro estado de derecho a favor del Movimiento Cooperativo Nacional aplicable a toda aquella persona que en forma libre y voluntaria se asocia a la Cooperativa y por consiguiente le son aplicables las obligaciones que emanan de la ley.

Es esa política pública la que según nuestra opinión debió ser respetada en todo su alcance para así respetar la voluntad de la Asamblea Legislativa, ya que lo contrario sería una burla a lo ya legislado. De esa política pública nacen las obligaciones de los socios dueños a base de las cuales la Cooperativa prestó un dinero y que resulta ser obligaciones que no pueden ser menoscabadas y que son asumidas cuando la persona decide en forma libre y voluntaria asociarse a este tipo de organización.

\section{Conclusiones:}

a) A pesar de que la socia de la cooperativa de ahorro y crédito hizo uso de su derecho a solicitar la protección de su empleo a través de la prohibición que impide que el patrono alegadamente la despidiera sin justa causa, el uso de ese derecho no puede menoscabar el acto cooperativo y los deberes que la ley le impone al socio de cumplir con sus obligaciones contractuales y pecuniarias que contrajo con la cooperativa.

b) La determinación judicial al resolver que por ser la controversia una de índole laboral merecía un proteccionismo a favor del obrero y en contra de los derechos contractuales, legal y sociales que surgieron al adherirse libre y voluntariamente como socia a la cooperativa nos fuerza a concluir que tal proteccionismo es contrario a la política pública en materia de cooperativismo y de las obligaciones legales que nacen de la Ley 255-2002, supra, del contrato de préstamo suscrito, de la libertad de contratación y del principio doctrinario de la autonomía de la voluntad que rige el derecho de obligaciones y contratos.

c) Las determinaciones de ambos Foros Judiciales no fueron correctas ya que la política pública creada por la Ley de la Mesada o Ley 80, supra, está dirigida a desalentar los despidos injustificados estableciendo el mecanismo que está disponible al trabajador que así desee utilizarlo, pero en forma alguna se puede afirmar que la Asamblea Legislativa creó un derecho constitucional o que la Ley 80, supra, creó un derecho adicional o prohibición que le impida a una Cooperativa solicitar la intervención en las querellas presentadas por los trabajadores en reclamo de una mesada 
cuando lo reclamado surge de un contrato que se convirtió en la ley entre las partes.

d) La protección que los Foros Judiciales adoptaron a favor del obrero menoscabaron los derechos y obligaciones que surgen por voluntad entre las partes del Derecho Cooperativo y menosprecian el alcance del acto cooperativo que forma parte de la política pública adoptada por el Gobierno de Puerto Rico.

e) Tales decisiones judiciales no fueron la mas adecuada ya que las decisiones están basadas en interpretaciones sobre el alcance de la ley que no hemos podido identificar ni del propio texto de ley ni de su historial legislativo como tampoco del propio derecho positivo. Mas bien se trata de una ley especial que desalienta las acciones de despido sin que exista una causa justa que es la única protección que surge de la política pública contemplada en la Ley 80, supra.

f) Al presente, en nuestro estado de derecho, no existe legislación que le impida o establezca una prohibición absoluta a la Cooperativa de solicitar remedios de ejecución de una sentencia en cobro de dinero y menos negarle el derecho de intervenir en el pleito o querella presentada por la socia en un caso donde obviamente dicha parte tiene unas expectativas de obtener un remedio económico conforme debe surgir de las alegaciones de su querella.

El comentarista y abogado, Delgado Zayas, Ruy, en su Libro, "Apuntes para el Estudio de la Legislación Protectora del Trabajo en el Derecho Laboral Puertorriqueño", Revisión 2001, San Juan, Puerto Rico, 132p., editorial no identificada, afirma:

"La legislación que rige el despido de empleados en la empresa privada, ya sea de empleados por tiempo determinado o indeterminado, lo que provee hasta el presente para el despido injustificado, es un remedio económico..."(Subrayado suplido).

Refiérase además a: Aureo Rivera v. Security National Insurance, 106 D.P.R. 517 (1977); Ariel Arroyo v. Rattan, 117 D.P.R. 35 (1986); Long v. Tribunal, 72 D.P.R. 788 (1951) y Padilla v. Centro Gráfico, 144 D.P.R. 952 (1988). En todos estos casos, el Tribunal Supremo de Puerto Rico resuelve que el único remedio que tiene el trabajador bajo la Ley 80, supra, es el remedio económico y por ende ningún otro derecho le es reconocido. 
En Alvira Cintrón v. SK F, 97 J.T.S. 40, el Tribunal Supremo de Puerto Rico resolvió que cuando se trata de una indemnización por despido injustificado el Artículo 10 de la enmendada Ley 80, supra, no permitía descuento alguno de nómina sobre dicha indemnización teniendo el patrono que entregar íntegramente su monto total al empleado. Igual ocurrió en Aureo Rivera, supra, donde el Tribunal Supremo resolvió que el único remedio compensatorio en relación con el despido de un empleado contratado sin tiempo determinado en violación a la Ley de Relaciones del Trabajo era el provisto expresamente en dicha Ley ya que el Legislador no había provisto ninguno otro. Por lo que en nuestra opinión, si la Asamblea Legislativa así lo hubiese dispuesto, existiría una prohibición expresa contra terceros para que no intervinieran en casos de reclamaciones por despido injustificados y además hubiese establecido igualmente una prohibición para que la indemnización que pudiera recibir el trabajador no pudiera ser embargada, lo que no es una acción llevada a cabo por quien tiene la facultad y el poder constitucional para legislar y no desde el estrado.

\section{Referencias}

Aguayo Pomales v. R \& G Mortgage, 169 D.P.R. 36, 43 (2006)

Alfredo Lamenza, El acto cooperativo, publicado por la Red RULESCOOP (2017)

Alvira Cintrón v. SK F, 97 J.T.S. 40

Antonio Salinas Puente, Derecho cooperativo, Doctrina, jurisprudencia, codificación, Editorial Cooperativismo, México, 1954, p.127

Aponte Caratini v. Román Torres, 145 D.P.R. 477 (1998)

Ariel Arroyo v. Rattan, 117 D.P.R. 35 (1986)

Aureo Rivera v. Security National Insurance, 106 D.P.R. 517 (1977)

Carta Jurídica de San Juan, II Congreso Continental de Derecho Cooperativo, San Juan de Puerto Rico 1976, Revista de Idelcoop, Año 1976, Vol. 3, № 11

Código Civil de Puerto Rico, Artículos 1044 y 1631, 31 L.P.R.A. Secs. 2994 y 4511.

Collazo Vázquez v. Huertas Infante, 2000 T.S.P.R. 91, 171 D.P.R. 84. 
Constitución de Puerto Rico, Carta de Derechos, Secciones 16, 17 y 18.

Cooperativa de las Américas: Tomado de http://empresaytrabajo.coop

Elsa Cuesta, en el Manual de Derecho Cooperativo, Ed. Abaco, Bs. As., 2000

Freire Ayala v. Vista Renta to Own, Inc., 2006 J.T.S. 172.

lacovino, Hugo Horacio (2006). El acto cooperativo a treinta años de vigencia en la Argentina. Documento de Trabajo № 146, Universidad de Belgrano

J.A. Cuevas Segarra, Tratado de Derecho de Procedimiento Civil, Tomo I, pág. 427 (Publicaciones J.T.S. 2000)

Ley Núm. 2 de 17 de octubre de 1961, 32 L.P.R.A., Sec. 3118.

Ley 43 de 25 de abril de 1930

Ley 80 de 30 de mayo de 1976, 29 L.P.R.A. Secs 185 A.

Ley Número 239 de 1 de septiembre de 2004, Ley General de Sociedades Cooperativas.

Ley Número 255 de 28 de octubre de 2002, según enmendada, Ley de Sociedades Cooperativas de Ahorro y Crédito de 2002.

Long v. Tribunal, 72 D.P.R. 788 (1951)

Lucero v. San Juan Star, 159 D.P.R. 494, 503-504 (2003)

Medina Nazario v. McNeil Healthcare, LLC, 194 D.P.R. 723 (2016)

Mercado Cintrón v. Zeta Comm., Inc., 135 D.P.R. 737 (1994)

Organización de las Naciones Unidas (O.N.U.) (2001). Resolución 56/14 de la 88va. Sesión Ordinaria. New York, N.Y.

Organización Internacional del Trabajo (OIT) (2002). Resolución Número 193 sobre la Promoción de las Cooperativas.

Padilla v. Centro Gráfico, 144 D.P.R. 952 (1988) 
Pastorino, Roberto Jorge, Teoría General del Acto Cooperativo, INTERCOOP Editora Cooperativa Ltda., Buenos Aires, 1993, p. 27 y 34

Patiño Chirino v. Parador Villa Antonio, 2016 TSPR 200, 196 D.P.R. (2016)

Quirós v. ITT, 108 D.P.R. 536 (1979).

R. Mix Cocrete v. R. Arellano \& Co., 110 D.P.R. 869 (1981)

Reglas de Procedimiento Civil de Puerto Rico, 32 L.P.R.A., Ap. V (2009)

Resolución 56/14 de la Organización de las Naciones Unidas (2001).

Resolución Número 193 sobre la Promoción de Cooperativas de la Organización Internacional del Trabajo (OIT) (2002).

Ríos v. Industrial Optic, 155 D.P.R. 1 (2001)

Rivera v. Insular Wire Products Corp., 140 D.P.R. 912, 923-924 (1996)

Ruy Delgado Zayas, en su Libro, "Apuntes para el Estudio de la Legislación Protectora del Trabajo en el Derecho Laboral Puertorriqueño”, Rev. 2001, San Juan, Puerto Rico

Tamayo Sáez, Manuel (1997), La nueva administración pública: El análisis de las políticas públicas. Madrid, España, Alianza Universidad.

Vicente Géigel Polanco, Bases, Naturaleza y Caracteres de la Legislación Social, publicado en el Libro, Legislación Social de Puerto Rico, edición 1944 del Departamento del Trabajo de Puerto Rico, Negociado de Publicaciones y Educación Obrera, San Juan, Puerto Rico. 